\title{
Central funding for Cochrane Canada must continue
}

\author{
John Fletcher MB BChir MPH
}

$\mathrm{T}$ he Canadian Institutes of Health Research (CIHR) are contemplating withdrawing funding for Cochrane Canada. At this year's Cochrane Canada Symposium, it was announced that CIHR had given notice that funding would no longer be available to support the centre as of September. This decision would end more than 10 years of central funding for the infrastructure that supports the Cochrane Collaboration in Canada.

The Cochrane Collaboration bears the name of an English epidemiologist who, in 1979, noted that there was more to be gained from collecting together and applying existing medical research than from undertaking further research uninformed by the past. ${ }^{1}$ This vision caught the imagination of academics in the United States, United Kingdom and Canada. In 1992, under the chairmanship of Canadian Professor David Sackett, the collaboration was formed. Its philosophy: that the task of building a library of systematic reviews and the benefits of this knowledge demanded global collaboration and that no single institution or country should be regarded as the owner. The purpose of the collaboration was to promote a systematic approach to reviewing the medical literature; its emphasis was on comprehensiveness and quality to produce as unbiased a measure of the effectiveness of a drug, operation or intervention with as little statistical uncertainty as possible. The methods for undertaking these reviews were not widely understood at the time. Canadian academics have been responsible for much of the work of cataloguing, teaching and promoting the science of systematic reviews and meta-analysis that underpin current policies of the Canadian Agency for Drugs and Technologies in Health, the Common Drug Review and the Public Health Agency of Canada.

No single institution could have undertaken the 6000 or so reviews now contained in the Cochrane Library - each review has cost about Can $\$ 100000$, using local research to contribute to this global effort. Each review is contributed to the library free of charge, but the coordination and quality assurance of the reviews is overseen by review groups and national coordinating centres. Canada is the second largest contributor of reviews (10\%), and reaps the benefits of access to $100 \%$ of the knowledge generated. Cochrane Canada supports 650 reviews, overseeing 5 review groups in subject areas such as hypertension and musculoskeletal disease, as well as developing methods to reduce bias and promote equity. The UK government supports Cochrane UK with $£ 5.3$ million (a little over Can $\$ 10$ million). The Australian government supports the Australasian Cochrane Centre with \$A2 million (Can\$2 million), about the same as Canada’s support.

Detractors would say that many of the topics reviewed in the Cochrane Library are not priorities for CIHR, and that reviews are not done quickly enough to provide policy answers to today's questions. To be fair, the same may be said of much CIHRfunded research. Although reviews of herbal remedies and acu- puncture contributed by other countries may not be mainstream, what could be more relevant than the Canadian reviews on hypertension, backache and arthritis? Rapid reviews may give a timely answer, but quality can suffer. Fortunately, tomorrow's priorities are often anticipated by today's Cochrane reviews, which can form the basis for future high-quality rapid reviews. Although some may balk at the Cochrane Collaboration entering into a partnership with commercial publisher Wiley-Blackwell, we should not conflate the separate processes of research and publication. Without a publisher, Cochrane reviews could not be widely disseminated. Access to the Cochrane Library is by subscription and has been since the publication of the first edition. Some countries and regions consider the Cochrane Library so valuable that they pay for access for all citizens (e.g., Norway, Western Australia) or all health professionals (e.g., UK). A national licence for Canada would probably cost little more than what is already paid by Canadians and Canadian institutions.

The Canadian Institutes of Health Research may regard spending on infrastructure as detracting from its ability to fund new research directly, but both are needed. Part of CIHR's mandate is to "excel, according to internationally accepted standards of scientific excellence, in the creation of new knowledge and its translation into improved health for Canadians."2 Creating and translating knowledge into practice requires organization. As Archie Cochrane noted:

It is surely a great criticism of our profession that we have not organized a critical summary, by specialty or subspecialty, adapted periodically, of all relevant randomized control trials.

Cochrane Canada exemplifies this organized effort of international scientific excellence, creating new knowledge and translating it into Canadian practice. What better use could there be of Can\$2 million - $0.2 \%$ of CIHR's budget?

Canada showed leadership when it helped found the Cochrane Collaboration. It would be better for this leadership to continue through CIHR's support of universal access to Cochrane's valuable body of knowledge than for Canada to be the first founding member to withdraw central funding.

\section{References}

1. Cochrane AL. 1931-1971: a critical review with particular reference to the medical profession. In: Teeling-Smith G, Wells N, editors. Medicines for the year 2000. London: Office of Health Economics; 1979:1-11.

2. Our mandate. Ottawa: The Canadian Institutes of Health Research; 2013. Available: www.cihr-irsc.gc.ca/e/7263.html (accessed 2015 July 15).

Competing interests: See www.cmaj.ca/site/misc/cmaj_staff.xhtml

Affiliation: Editor-in-Chief, CMAJ

Correspondence to: $C M A J$ editor, pubs@cmaj.ca

CMAJ 2015. DOI:10.1503/cmaj.150830 